\title{
O Processo de Bolonha e a internacionalização do ensino superior na Europa: uma experiência multicultural $^{1}$
}

\section{The Bologna Process and the internationalization of Higher Education in Europe: a multicultural experience}

\section{El Proceso de Bolonia y la internacionalización de la Educación Superior en Europa: una experiencia multicultural}

\author{
António Cachapuz ${ }^{2}$
}

DOI:http://dx.doi.org/10.20435/serie-estudos.v0i0.1385

\begin{abstract}
Resumo: O objetivo deste estudo é contribuir para uma reflexão conjunta sobre problemáticas de internacionalização das instituições de ensino superior (IESs) no quadro do Espaço Europeu de Ensino Superior (EEES). Embora a construção do EEES/ Processo de Bolonha (PB) (1999) seja hoje em dia frequentemente criticada como projeto político legitimando a lógica economicista no quadro da globalização neoliberal em curso, e não ao serviço do desenvolvimento humano de carácter cooperativo e emancipatório, é inegável que algo se conseguiu na internacionalização das IESs na Europa. Neste trabalho, por meio de uma análise de conteúdo documental, analisam-se estratégias seguidas pelas IESs aderentes ao PB; por exemplo: (i) organização curricular de modo a mais facilmente transferirem internacionalmente as aquisições curriculares obtidas por intermédio de um novo sistema de unidades de crédito transferíveis (ECTS); (ii) oferta de novos programas de mobilidade (Erasmus +) para docentes e estudantes; (iii) processos de integração transnacionais em redes. Num segundo tempo, apresentam-se cenários possíveis de internacionalização. Os cenários, embora não sejam únicos, representam possibilidades de entender a internacionalização e ajudam a refletir sobre o campo de estudo e a partilha de ideias. Neste contexto, especifica-se o caso da universidade de Aveiro, Portugal, que integra a Rede Ibero-Americana GIEPES. Nas notas finais, discute-se o eventual interesse na criação de um espaço latino-americano de Educação Superior.
\end{abstract}

Palavras-chave: internacionalização; Processo de Bolonha; Universidade de Aveiro.

\footnotetext{
${ }^{1}$ Este trabalho é financiado por Fundos Nacionais por meio da Fundação para a Ciência e a Tecnologia (FCT), I.P., no âmbito do projeto UID/CED/00194/2019.

2 Universidade de Aveiro, Centro de Investigação em Didática e Tecnologia na Formação de Formadores (CIDTFF), Aveiro, Portugal.
} 
Abstract: This study aims to contribute to a joint reflection on problems of internationalization of Higher Education Institutions (HEIs) in the context of the European Higher Education Area (EHEA). Although the construction of the EHEA/Bologna process (BP) (1999) is nowadays often criticized as legitimizing political project in the context of neo-liberal globalization in progress, and not at the service of human development of cooperative and emancipating character, it is undeniable that something has been achieved in the internationalization of HEls in Europe. This paper, through a content analysis of documents, discusses strategies followed by the HEls; for example: (i) the curriculum organization in order to more easily transfer internationally curricular acquisitions obtained through a new system of transferable credit units ECTS (European Credit Transfer System); (ii) new mobility programs (Erasmus +) for teachers and students; (iii) cross-border integration processes in networks. Secondly, it presents possible scenarios of internationalization. The scenarios, though not unique, represent opportunities to understand the internationalization and may help to reflect on the field of study and sharing of ideas. In this context, it is specified the case of the University of Aveiro, Portugal, integrating the Iberoamerican Network GIEPES. In the end notes, possible interest in creating a Latin American Higher Education space is discussed.

Keywords: internationalization; Bologna Process; Aveiro University.

Resumen: El objetivo de este estudio es contribuir a una reflexión conjunta sobre temas de internacionalización de las Instituciones de Educación Superior (IESs) en el contexto del Espacio Europeo de Educación Superior (EEES). Aunque la construcción del EEES/Proceso de Bolonia (PB) (1999) hoy en día a menudo se critica como legitimación de proyecto político en el contexto de la globalización neoliberal, y no al servicio del desarrollo humano de carácter cooperativos y emancipador, es innegable que algo se ha logrado en la internacionalización de las IESs en Europa. En este trabajo, a través de un análisis de contenido de documentos, se discuten estrategias seguidas por las IESs; por ejemplo: (i) organización de plan de estudios para transferir internacionalmente las adquisiciones curriculares obtenido por medio de un nuevo sistema de unidades de crédito transferibles (ECTS); (ii) oferta de nuevos programas de movilidad (Erasmus +) para profesores y estudiantes; (iii) procesos de integración transnacionales en redes. En un segundo momento se presentan escenarios posibles de la internacionalización. Los escenarios, aunque no sean únicos, representan una oportunidad para entender la internacionalización y ayudan a reflexionar sobre el campo de estudio y el compartimiento de ideas. En este contexto, se especifica el caso de la Universidad de Aveiro, Portugal, integrando la Rede Ibero-Americana GIEPES. En las notas finales, se analiza el posible interés en la creación de un espacio de Educación Superior de América Latina.

Palabras clave: internacionalización; Proceso de Bolonia; Universidad de Aveiro.

\section{INTRODUÇÃO}

Desde a Idade Média, a internacionalização está no ADN das instituições de ensino superior (IES) na Europa. Por certo, não nos termos, ritmo e alcance como hoje a conhecemos. Nem por isso a internacionalização esteve então ausente. Que o digam as universidades de Salamanca, Bolonha, Coimbra, Praga, Florença, Oxford, Paris ou Heidelberg, entre outras, que assistiram nessa época a um cor- 
rupio de idas e vindas de estudantes, alguns deles bem ilustres, aquilo que hoje se chamaria à escala própria de mobilidade. Se me é permitido um excesso, diria que a criação e difusão da Universidade é um dos maiores legados que a Europa deu ao mundo, pelo menos ao mundo do conhecimento.

De acordo com Cachapuz (2009), a partir do século XVII, começou a surgir o conceito de Universidade vs. Estado-Nação. A universidade visou então a formação de quadros dirigentes, uma característica que ainda não perdeu de todo (mas ganhou outras). Caraça (2003, p. 63) aponta que a universidade

[..] surge como reação ao modelo iluminista transportado pela revolução Francesa: a divisão e especialização dos saberes através da criação de grandes escolas sectoriais e profissionais. A nova universidade constituía-se como um foco nacional de civilização e cultura, propondo a indivisibilidade dos saberes úteis ao funcionamento do estado-nação. É neste contexto que advém a assimilação de universidade com universalidade.

A dimensão de internacionalização do conhecimento espalha-se rapidamente pela Europa da revolução industrial. Mais perto de nós, com início no século XX, sobretudo após a Segunda Guerra Mundial, o ethos da universidade modifica-se substancialmente com a entrada em cena (de forma gradual) de vários aspetos estruturantes: massificação; democratização no acesso; diversificação de percursos académicos; alteração nos regimes de autonomia; aumento da responsabilidade social; fontes alternativas de financiamento; novos cenários tecnológicos/tecnociência; perda de exclusividade como fonte de conhecimento; pesquisa intensiva; internacionalização. Claramente, há agora uma abertura à sociedade e à economia (CACHAPUZ, 2009, p. 15). É nos EUA que este novo conceito de universidade se afirma em pleno, elegendo como nova e importante função assistir às necessidades de um novo parceiro, o mercado. "Os modos de governo e de gestão universitário alteram-se. Este novo modelo de universidade não se preocupa só com graus, mas também com o novo conhecimento que consegue transferir para as instituições de mercado. Para o bem e para o mal" (CARAÇA, 2003, p. 64). O prestígio dessas universidades norte-americanas, as chamadas research universities (não confundir com os community colleges), é inquestionável e traduz o triunfalismo da orientação de recorte neoliberal. E é precisamente neste contexto que na Europa surge a necessidade de criação do Espaço Europeu de Ensino Superior (EEES) que the confira a competitividade necessária face aos EUA. No início dos anos 1990, e pela primeira vez, o número de estudantes europeus estudando nos Estados Unidos 
da América excedia o número de estudantes americanos estudando na Europa. Sem melhorar a competitividade internacional do sistema (dimensão económica), não era só a Europa do conhecimento que estava na berlinda. Era a própria construção política da União Europeia (então em curso) que ficava prejudicada (dimensão política). Não é por acaso que, logo em março de 2000, os líderes da União Europeia, na sua qualidade de estrutura política supranacional, reunidos em Lisboa, adotaram a chamada Agenda (ou Estratégia) de Lisboa, um plano estratégico de desenvolvimento para a União Europeia fortemente marcado por conceitos económicos, em particular a ideia de construir uma economia do conhecimento mais competitiva e dinâmica do mundo, antes de 2010, capaz de um crescimento económico duradouro acompanhado por uma melhoria quantitativa e qualitativa do emprego e uma maior coesão social, objetivos hoje em dia longe de serem devidamente alcançados. Na Europa, o processo de internacionalização já vinha sendo acelerado com programas isolados de mobilidade dos estudantes nos anos 1980 (programas Erasmus) e aprofundou-se com a Declaração de Bolonha, em 1999, e posterior transposição para os países parceiros nos anos seguintes, instrumentos estratégicos do desenvolvimento do EEES. Ou seja, o EEES não surge só como uma consequência da globalização económica em curso, mas também um processo cuja lógica é ele mesmo de caráter globalizante, pelo menos à escala europeia.

Num registo mais sociológico, o EEES, ao envolver uma forte componente de internacionalização, constitui um elemento de enriquecimento e abertura de novas e diversas possibilidades entre culturas. Numa Europa cujo histórico do século XX foi atravessado por nacionalismos exacerbados de má memória, os contributos do EEES na aproximação de culturas e respeito pela sua diversidade não são de somenos importância. Deste modo, tem sentido afirmar que a construção do EEES vai mais além dos seus pressupostos neoliberais e também deve ser enriquecida como uma experiência multicultural de que ainda pouco se conhece sobre o seu impacto.

A finalidade deste estudo é contribuir para a compreensão das problemáticas de internacionalização das IESs europeias no quadro da construção do EEES, em particular, as estratégias de internacionalização explorando a estrutura transnacional de graus académicos, integração das diferentes dimensões de internacionalização num plano institucional, bem como várias disfunções identificadas.

A abordagem metodológica seguiu uma orientação de pesquisa qualitativa de natureza interpretativa (FLICK, 2009). A análise seguiu princípios teórico-meto- 
dológicos da Revisão Sistemática de Literatura (BERWANGER et al., 2007), tendo como fontes institucionais relatórios de atividades da Universidade de Aveiro, relatórios da Comissão Europeia e extensa investigação sobre problemáticas do EEES (ver bibliografia) pertinentes para a finalidade do estudo.

Na organização do estudo, esclarecida qual a sua finalidade e contextualizados, ainda que de modo sumário, os pontos de partida na criação do EEES, no que se segue, apresentam-se cenários possíveis de internacionalização. Os cenários, que não são únicos, representam possibilidades de entender a internacionalização e ajudam a refletir sobre o campo de estudo e a partilha de ideias. Particular atenção é dada a espaços transnacionais de internacionalização em linha com os objetivos do estudo. No parágrafo seguinte, apresenta-se um exemplo de internacionalização, no caso da universidade de Aveiro, Portugal, uma das várias instituições de ensino superior integrando a Rede Latino-Americana GIEPES, cujo foco é precisamente a internacionalização nesse espaço geográfico. Neste exemplo, apresentam-se detalhes sobre as diferentes dimensões de internacionalização que devem fazer parte, de modo integrado, de um programa estratégico de internacionalização das IESs. Nas notas finais, discute-se o eventual interesse na criação de um espaço latino-americano de Educação Superior e eventuais vantagens e desvantagens da experiência do EEES para o efeito.

\section{CENÁRIOS DE INTERNACIONALIZAÇÃO}

A internacionalização não é um fim em si mesmo, mas sim um meio estratégico para promover e apoiar a qualidade das formações no sentido académico, difusão do conhecimento e como instrumento para aproximar povos e conhecer outras culturas no quadro de uma cidadania ativa, solidária e global (GACELÁVILA, 2006). Ou seja, a internacionalização como dimensão estratégica no ensino superior não existe (não deve existir) num vazio sociopolítico. O foco da internacionalização não é a mobilidade discente e docente, mas sim de que modo esta pode ser explorada para a melhoria do currículo e das aprendizagens, e não só para o benefício de alguns (WIT; HUNTER, 2015). Exceto numa visão instrumental (de recorte neoliberal), a internacionalização só tem verdadeiro sentido quando imersa num sistema de valores humanistas, defesa da diversidade cultural, ética de solidariedade e participação cívica em linha com os valores defendidos pela UNESCO. 
Na figura 1, apresentam-se vários cenários de internacionalização que, não sendo únicas possibilidades de organizar o conhecimento sobre o campo de estudo, ajudam a cruzar olhares sobre o espaço ocupado nesse campo pelo EEES, foco deste estudo.

Figura 1- Os cenários representam possibilidades de entender a internacionalização, que não são únicas e ajudam a refletir sobre o campo de estudo e partilha de ideias. Os valores humanistas e de cidadania são um 3o eixo que se sobrepõe aos cenários propostos

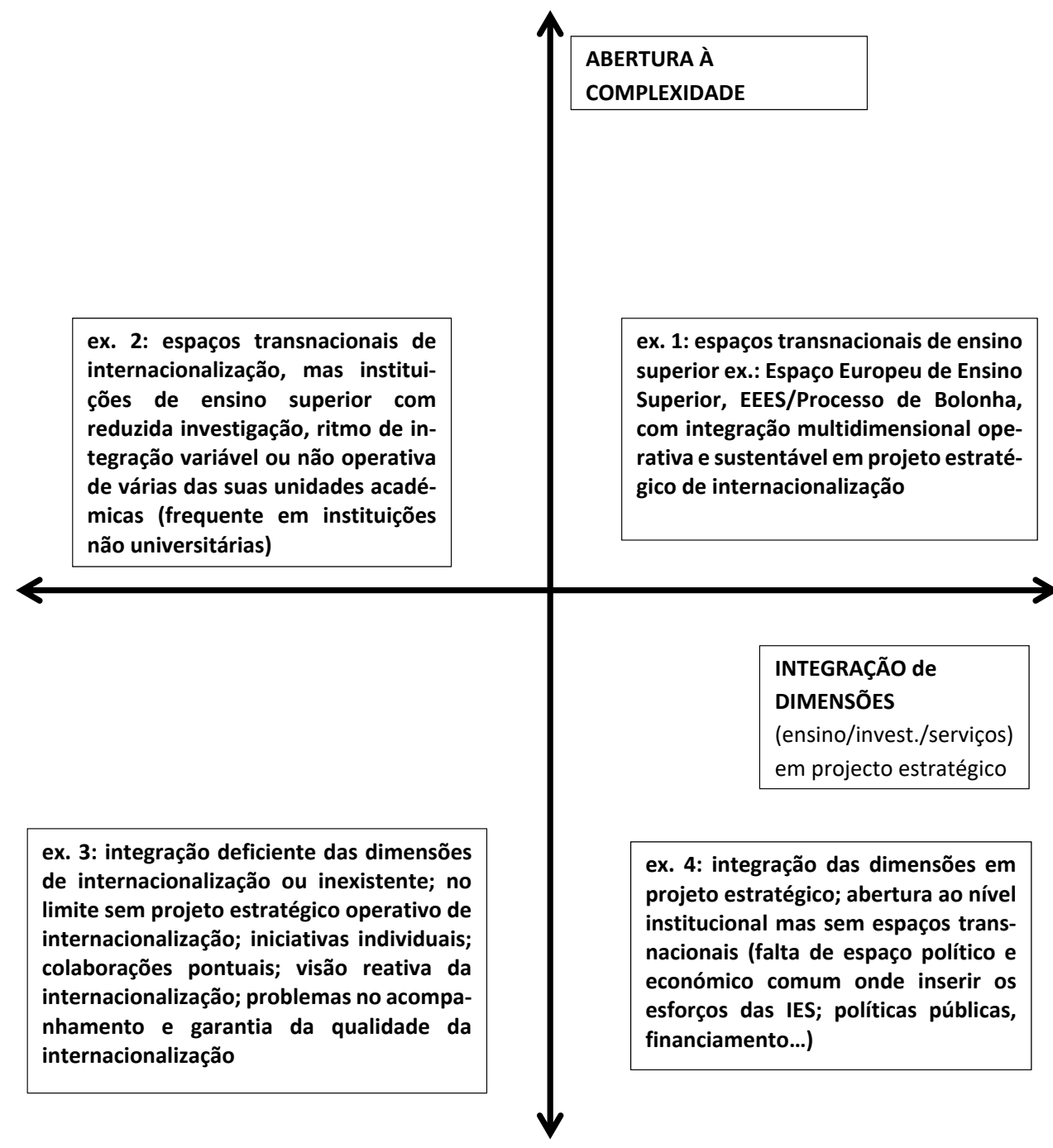

Fonte: Próprio autor. 
O seu sentido não é nem classificatório nem avaliativo, mas tão só de ajudar à compreensão do campo de estudo. O eixo de abertura à complexidade tem a ver com as dinâmicas de interdependência entre instituições de ensino superior e/ou países, incluindo espaços transnacionais, resultantes da multirreferencialidade (política, económica, cultural, conhecimento...) das diferentes experiências de internacionalização no quadro de uma epistemologia da complexidade. Naturalmente, sendo um contínuo de possibilidades, pode haver instituições e países com diferentes dinâmicas de internacionalização. O eixo da integração das dimensões de internacionalização é multidimensional e tem como lógica o conceito de internacionalização compreensiva de Hudzik (2011). Por isso mesmo, engloba de modo integrativo o ensino (p. ex., titulação conjunta de graus académicos dos estudantes estrangeiros, internacionalização do currículo...), a investigação (p. ex., redes institucionais de investigação, e não só colaborações pontuais e/ou individuais...), serviços (p. ex., serviços estruturados de apoio a estudantes estrangeiros, mobilidade internacional de funcionários, estruturas de garantia de qualidade do processo de internacionalização...) e sua articulação em um todo coerente no quadro de um projeto estratégico devidamente operacionalizado. Em cada eixo, a leitura segue um contínuo de possibilidades em função das dinâmicas das diferentes instituições, casos notórios do 10 e 20 exemplos (ver foco deste estudo).

Um dos instrumentos estratégicos da construção Espaço Europeu de Ensino Superior é o designado Processo de Bolonha, cujo ponto de partida foi a declaração de Bolonha (em homenagem à mais antiga universidade europeia), com data de 19 de junho de 1999 e assinada por 29 países. Hoje em dia, são já 48 países, cerca de 16 milhões de estudantes de 5.000 instituições de ensino superior. 0 desenvolvimento do processo não decorre de modo simétrico em todos os países participantes, nalguns deles com ritmos e alcance de integração variável, razão que nos leva a considerar as situações dos exemplos 1 e 2 (Figura 1), já que, apesar de as instituições pertencerem formalmente por via da sua pertença a país parceiro do EEES, são patentes as diferenças de desenvolvimento do processo, por exemplo em nível da investigação. De acordo com Wit e Hunter (2015, p. 2), "mesmo na Europa, considerada mundialmente como um exemplo de boas práticas de internacionalização, ainda há muito por fazer, existindo assimetrias nos resultados obtidos por diferentes países". 
Há uma extensa bibliografia académica sobre o Processo de Bolonha (ver, por exemplo, CROSIER; PURSER; SMIDT, 2007; DIAS SOBRINHO, 2007; PEREIRA; ALMEIDA, 2009, 2011; BJERKE, 2010; SURSOCK; SMIDT, 2010; ZGAGA, 2010, entre outros), além de estudos e relatórios técnicos oriundos da Comissão Europeia (por exemplo, SURSOCK; SMIDT, 2010; CROSIER; PURSER; SMIDT, 2007; COMUNICADO DE PARIS, 2018).

Resumem-se aqui os objetivos essenciais do Processo de Bolonha:

- Promover entre os cidadãos europeus a empregabilidade e a competitividade internacional do sistema europeu do ensino superior.

- Estabelecer um sistema de créditos transferíveis e acumuláveis (ECTS), comum aos países europeus, para promover a mobilidade mais alargada dos estudantes.

- Adotar um sistema baseado em três ciclos de estudos:

- 10 ciclo, com uma duração de seis a oito semestres (180 a 240 ECTS);

- 2o ciclo, com a duração de um ano e meio a dois (90 a 120 ECTS);

- 3o ciclo, com duração de dois anos, conferindo o título de Mestre (MFE, MF, MBA e MS).

- Implementar o suplemento ao diploma com titularidade académica reconhecida.

- Promover a mobilidade dos estudantes (no acesso às oportunidades de estudo e formação, bem como a serviços correlatos), professores, investigadores e pessoal administrativo (reconhecimento e valorização).

- Promover as dimensões europeias do ensino superior, em particular:

- Desenvolvimento curricular;

- Cooperação interinstitucional;

- Mobilidade de estudantes, docentes e investigadores;

- Programas integrados de estudo, de formação e de investigação.

Dois dos aspetos estruturantes do Processo de Bolonha foram as convergências entre países sobre a estrutura de graus do ensino superior e o estabelecimento de um novo conceito de unidade de crédito transferível (ECTS), tendo como base todo o trabalho do aluno, e não só o tempo letivo, de modo coerente com uma nova abordagem pedagógica centrada no aluno/aprendizagem. No que respeita à estrutura de graus, o ponto de partida foi o 1 ㅇ ciclo (de Bolonha) correspondendo à licenciatura (em geral, 180 ECTS, 3 anos); o 2o ciclo ao Mestrado 
(em geral, 120 ECTS, 2 anos); e o 3o ciclo ao doutoramento (em geral, 180 ECTS, 3 anos). No entanto, fruto de contextos específicos dos diferentes Estados-Membros e instituições de ensino superior, há diferentes configurações seguidas no que respeita à estrutura de graus ( 1 ㅇ e 2 o ciclo de estudos), em que há várias versões em curso em diferentes países quanto ao número de anos, por exemplo: 3+1; 3+2; 4+1; 5 (ciclo único, frequente no caso das formações em Engenharia, Arquitetura, Medicina...). Tal diversidade é benéfica, já que assegura o pluralismo de contextos/culturas diferenciadas, uma marca de água da Europa, embora mantenha a convergência. Por outro lado, a institucionalização dos créditos ECTS, no entender de alguns um "cartão de crédito educacional", facilitou (e muito) a mobilidade dos estudantes e reconhecimento dos seus graus por outros países.

Embora seja inegável que um dos aspetos mais positivos do Processo de Bolonha seja a promoção da internacionalização no ensino superior, nem por isso ele deixa de ser objeto de justas críticas. Assim, a empregabilidade (um objetivo central da declaração de Bolonha) é um dos aspetos com maior dificuldade de realização (ver SURSOCK; SMIDT, 2010). Sendo certo que há razões de ordem económica que se sobrepõem em nível europeu, falta esclarecer (i) até que ponto também a "desconfiança" de empregadores em relação a formações mais curtas de licenciatura (3 anos) não dificulta a empregabilidade; (ii) dificuldade na articulação entre ciclos de Bolonha, em particular entre o 10 e o 20 ciclo, com potenciais problemas na formação dos estudantes; (iii) ou ainda a exigência de um mestrado em várias formações pode afastar estudantes (ou diminuir seu potencial de acesso) do mercado de trabalho por razões meramente económicas (as taxas dos mestrados são elevadas e podem introduzir consequências em nível da democratização do acesso à formação). Acresce que o processo foi acompanhado pelo aumento da burocracia dos processos internos e por uma alteração dos processos de governança das instituições de ensino superior, com uma desvalorização da autonomia universitária em boa parte devido a que as decisões estratégicas são agora tomadas, ou também tomadas, por atores supranacionais ou externos à universidade. Para Oliveira e Holland (2008), o processo em curso visa criar a Universidade Empresa ao serviço da reorganização internacional do trabalho e satisfazer a troca de serviços defendida pela Organização Mundial de Comércio, considerando que o processo "corre o risco de reproduzir algumas das características mais negativas da educação de massa fordista, da hierarquia weberiana 
e da vigilância tanto foucaultiana como taylorista" (OLIVEIRA; HOLLAND, 2008, p. 20). Maassen (2008, p. 94) é outra voz crítica, considerando que:

[...] o processo em curso inscreve-se sim numa orientação de índole economicista no quadro da globalização neoliberal (Universidade Empresa): ou seja, a pretensão de ser o mercado a definir o que as instituições de ensino superior público, em particular as universidades, devem fazer e como se organizar. Em síntese, o mercado como instrumento regulador das políticas públicas, neste caso das políticas de educação. O novo modelo enfatiza, "management" e empreendorismo mais do que liberdade académica, democracia interna e papel organizador das disciplinas académicas.

Por esclarecer está ainda de que modo a criação do EEES teve impacto positivo nas vertentes da cidadania ativa, solidária e global dos seus intervenientes. Questões em aberto que, até à data, não têm tido respostas convincentes.

\section{UM EXEMPLO DE INTERNACIONALIZAÇÃO}

De que modo os esforços de internacionalização feitos por universidades europeias têm sido traduzidos em resultados práticos?

A Europa é considerada um parceiro internacional de destaque no âmbito da internacionalização do ensino superior. Em nível geral, é possível encontrar informação útil sobre a temática da internacionalização no ensino superior nos vários relatórios da União Europeia sobre o tema; por exemplo, vários relatórios Trends da União Europeia ou, mais recentemente, no comunicado da Conferência Ministerial de Paris, maio de 2018. A par dessas iniciativas, surgem diversos projetos transnacionais ou até transcontinentais, como o de nove instituições de ensino superior da zona ibero-americana (rede GIEPES, coordenada pela UNICAMP/Brasil) desenvolvendo um projeto de investigação com foco na Internacionalização na educação superior em países da América Latina, Portugal e Espanha, visando ao melhor conhecimento dos processos de internacionalização em curso nas instituições parceiras, estreitar o diálogo institucional entre elas e a obtenção de dados comparativos eventualmente úteis para processos de decisão. Tal procura de novas inteligibilidades tem por pressuposto que "o valor prático de estudar o funcionamento dos sistemas educativos estrangeiros, no seu verdadeiro espírito e com precisão científica, é que, como resultado disso, estaremos melhor preparados para estudar e compreender o nosso" (SADLER, 1964, p. 313-4). 
Uma das instituições parceiras da rede GIEPES é a Universidade de Aveiro (UA), Portugal, uma jovem universidade (criação em 1973) fazendo parte do EEES. É uma universidade de média dimensão à escala europeia, com cerca de 14.000 alunos, 24\% de pós-graduação e 1.500 docentes (quase todos doutorados).

Inscrita na ordem de prioridades da UA, a internacionalização resulta das dinâmicas de atuação das suas três diferentes áreas de missão, a saber: ensino, investigação e cooperação com a sociedade. Tem, pois, um enquadramento multidimensional em convergência com a modernidade das políticas institucionais que internacionalmente se aplicam a este campo de atividade no ensino superior. Na lógica (discutível) da atribuição de rankings por agências internacionais, o posicionamento internacional da UA tem sido reconhecido por meio de inúmeros rankings. A UA encontra-se entre as 100 melhores universidades com menos de 50 anos de acordo com o ranking do Times Higher Education; é considerada uma instituição muito boa em termos de investigação, internacionalização e transferência do conhecimento, de acordo com o U-Multirank; e está entre as 500 melhores universidades do mundo de acordo com o Leiden Ranking.

Parte destes resultados devem-se ao esforço de internacionalização da UA orientado por um plano estratégico de internacionalização, sob a tutela direta de uma pró-reitoria e visando a sete objetivos centrais:

- Reforço da atratividade e integração internacional da oferta formativa da UA, quer através da disponibilização consistente de unidades curriculares em língua estrangeira, do aumento da oferta formativa em Inglês ao nível do 2 o e 3 응 ciclos, quer ainda pelo aumento e a consolidação de ofertas internacionais de qualidade, em modalidade de dupla titulação, com parceiros internacionais de excelência no ensino e na investigação;

- Estímulo à valorização internacional da produção académica da comunidade universitária da UA, por meio do incentivo à presença e publicação em fora internacionais de excelência;

- Aposta na consolidação de um ambiente de ensino-aprendizagem de vocação internacional, por meio da implementação de políticas e práticas de apoio ao acolhimento e integração adequada da comunidade internacional.

- Estímulo ao aumento das dinâmicas de realização de encontros científicos internacionais na Universidade de Aveiro, envolvendo parceiros internacionais, bem como agentes económicos locais, numa lógica de reforço da visibilidade da UA e da sua ligação à cidade e à região; 
- Estímulo e apoio à participação de docentes e investigadores da UA em projetos de investigação, inovação e demonstração financiados por programas internacionais (por exemplo, H2020);

- Desenvolvimento de uma cultura e de um contexto de oportunidades que estimulem todos os estudantes não falantes de Língua Portuguesa a investirem na sua qualificação para a aprendizagem do Português, durante o seu período de estudos na UA; e, em paralelo, estímulo aos falantes de Português a qualificarem-se numa outra língua além do Inglês, nomeadamente por meio da frequência de unidades extracurriculares de outras línguas, aproveitando a estrutura matricial de ensino e aprendizagem proporcionada pela UA.

- Aposta na mobilidade internacional.

De que modo tais objetivos se traduzem em resultados concretos de internacionalização? Tendo em conta as três dimensões da internacionalização (Fig. 1), apresenta-se uma súmula de aspetos para reflexão sobre o esforço feito pela UA em cada uma delas.

\section{- Dimensão Ensino:}

Em relação ao objetivo 1 (ver acima), à data, a UA oferece 387 unidades curriculares que referenciam o Inglês como a língua de lecionação, ou uma das línguas de lecionação, correspondendo a mais de um quarto das unidades curriculares genéricas da instituição. Para apoiar esta medida, a UA oferece cursos livres de línguas com um total de 1.544 inscrições, sendo 467 em Português como língua estrangeira (para estrangeiros) e 1.077 noutras línguas. Ao mesmo tempo, oferece programas doutorais lecionados em inglês em: Biologia, Ciência e Engenharia de Materiais, Ciências e Engenharia do Ambiente, Engenharia Eletrotécnica, Engenharia Informática, Nanociências e Nanotecnologia, Marketing e Estratégia. No que respeita ao objetivo 3 (acima), a UA desenvolveu uma rede de buddies para os novos estudantes internacionais selecionados, com o apoio da Associação Académica da UA, proporcionando uma política de acolhimento de proximidade. Em simultâneo, oferece um ano zero a estudantes internacionais, permitindo a aquisição quer de qualificações necessárias ao acesso aos cursos, quer de contribuições para uma integração efetiva dos estudantes internacionais no seio da academia (objetivo 6, acima).

Em complemento destas medidas, e no que à mobilidade internacional diz respeito (objetivo 7, acima), a UA tem investido nos últimos vinte anos na sua 
capacidade de captação de estudantes estrangeiros oriundos ou não de países europeus. Por exemplo, na abertura de vagas para alunos estrangeiros com Concurso Especial de Acesso e Ingresso para Estudantes Internacionais (CEAIEI), com o objetivo de ir ao encontro de diferentes calendários de candidatura para estudantes das diferentes geografias e hemisférios (no caso de estudantes brasileiros, dá-se equivalência ao ENEM). Ou ainda, ao abrigo do Estatuto do Estudante Internacional (Decreto Lei n. 36/2014), a criação de um contingente substancial de vagas específico para públicos internacionais e oferta de bolsas próprias a estudantes estrangeiros (50 bolsas incentivo). Quanto aos fluxos de mobilidade, sobretudo no quadro do programa ERASMUS +, apontam 585 estudantes incoming em 2017/2018, oriundos de 50 países - por exemplo, China (105); Espanha (72); Itália (71); Polónia (58); Alemanha (48); Brasil (26) - e 242 estudantes outgoing (em 2018, sobretudo Europa e Brasil). No caso dos docentes, cabe destacar a oferta de cátedras a docentes estrangeiros.

\section{- Dimensão Investigação}

A investigação na UA desenvolve-se no âmbito de 20 unidades de investigação reconhecidas e financiadas pela Fundação para a Ciência e a Tecnologia (FCT), nas mais variadas áreas científicas e com um equilíbrio inteligente entre a investigação dita fundamental e aplicada - 95\% dessas unidades de investigação obtiveram classificação de Muito Bom (12) e Excelente (7) na última avaliação internacional (2018) promovida e organizada pela FCT e integram a quase totalidade de investigadores da UA, como membros integrados ou colaboradores. A Universidade de Aveiro é um parceiro privilegiado de empresas e organizações nacionais e internacionais com as quais colabora em inúmeros projetos e para as quais fornece serviços substanciais. Uma boa parte do seu financiamento provém desses projetos e serviços externos.

A UA alcançou uma posição significativa entre as instituições de ensino superior em Portugal, sendo uma das melhores universidades em relação à qualidade das infraestruturas, capacidade de investigação e a excelência dos seus recursos humanos. Em apoio deste argumento, em 2017, 43 bolsas para os seus docentes/pesquisadores e 120 eventos internacionais (objetivo 4 acima); o número de publicações (objetivo 2 acima) em coautoria com outras instituições internacionais foi, em 2015, de 5.656 publicações, e o número de artigos de pro- 
fessores em revistas internacionais nos últimos 5 anos (2013/7) foi de 10.275. Desde 1998, a UA integra o Consórcio Europeu de Universidades Inovadoras (ECIU), um cluster internacional de universidades de investigação, com uma ênfase coletiva sobre inovação, criatividade e impacto na sociedade, que visa impulsionar o desenvolvimento de uma economia baseada no conhecimento (objetivo 5 acima). Sendo a investigação da UA sua forte vertente, decorrem atualmente 107 projetos de investigação e de transferência de tecnologia, na sua grande maioria financiados por programas europeus e/ou internacionais no quadro de convênios de internacionalização desenvolvidos, por exemplo: The Discoveries Centre for Regenerative and Precision Medicine, parceria da University College de Londres, da Universidade do Porto, da Universidade de Aveiro, da Universidade de Lisboa e da Universidade Nova de Lisboa. Existem várias articulações com universidades brasileiras, por exemplo, a UA preside ao Grupo Tordesilhas, uma rede formada por 55 universidades - 29 do Brasil, oito de Portugal e 18 da Espanha - com o objetivo de promover a cooperação no campo da ciência e tecnologia. Ou ainda, a UA integra também o chamado Grupo Coimbra de Universidades Brasileiras. As áreas do conhecimento envolvidas nos diversos programas são: Saúde, Ciências e Engenharia dos Materiais, TIC, Robótica, Mar, Ambiente, Alterações Climáticas, Floresta, Cidades Inteligentes, Educação, Empreendedorismo, Geociências, Astronomia, Energia, Engenharia Civil, Biologia Marinha, Turismo, Química, Economia Circular e Biotecnologia.

\section{- Dimensão Serviços}

Sem um forte apoio do pessoal administrativo e técnico da UA às atividades de ensino e investigação acima referidas, não teria sido possível a abertura à internacionalização e a consecução dos sete objetivos da UA acima formulados. Não por acaso, faz parte da política de formação de recursos humanos da UA uma permanente atualização do seu pessoal não docente: em 2017, foram oferecidas 17 bolsas para formação de funcionários/técnicos. No domínio específico da internacionalização, os serviços da UA: (i) asseguram uma comunicação adequada por meio de site bilingue, em Português e Inglês. No entanto, em backoffice, qualquer página ligada à instituição pode ser definida e configurada para três línguas: Português, Inglês e Espanhol. Grande parte da informação pode ser acedida nos 2 primeiros idiomas, uma parte também no terceiro, e para alguma informação 
específica, num quarto (o Chinês/Mandarim); (ii) outra área estratégica é o acoIhimento e a integração flexível para estudantes internacionais, contemplando desde logo o reforço da comunicação e do apoio no processo de candidatura, e no ajustamento das atividades de acolhimento e integração que deem resposta às suas necessidades específicas, promovendo a interação de todos os estudantes na comunidade da UA; (iii) ainda ao nível da comunicação, a participação em campanhas especificamente orientadas para a atração de estudantes estrangeiros nos mercados preferenciais; (iv) não menos relevante para a integração dos estudantes é o serviço social, em particular o apoio psicológico e a consulta médica, oferecidos a todos os membros da UA, incluindo estudantes estrangeiros.

\section{NOTAS FINAIS}

No dealbar do século XXI, a internacionalização é (a par da inovação), reconhecidamente, uma tendência global dos sistemas de educação superior qualquer que seja a geografia para onde se olhe. A Conferência Inter/Ministerial de Paris, em maio de 2018, reforça isso mesmo e acrescenta "a necessidade de melhorar a implementação de valores fundamentais, especialmente democracia, tendo em conta que os padrões de educação superior promovem valores de paz e liberdade" (COMUNICADO DE PARIS, 2018).

O sucesso do Espaço Europeu de Ensino Superior é um bom exemplo de internacionalização transnacional, sem pretender ser a única via possível de aprofundamento da convergência de sistemas de ensino superior ao nível transnacional. Na verdade:

A internacionalização é impulsionada por uma combinação dinâmica e em constante evolução de justificativas políticas, econômicas, socioculturais e acadêmicas. Estas justificativas podem tomar diferentes formas e dimensões nas diferentes regiões e países e em instituições e seus programas. Não há um modelo que se adapta a todos. As diferenças regionais e nacionais são variadas e em constante evolução, e o mesmo é verdade no seio das instituições. (WIT; HUNTER, 2015, p. 2).

Mas o melhor conhecimento da experiência europeia pode ter interesse para a criação do Espaço Comum Latino-Americano de Educação Superior, como defendido por Lamarra e Garcia (2015, p. 60): "assinalamos com ênfase que o processo de Bolonha pode constituir um quadro adequado para estudar os processos 
de convergência, não para adotá-los acriticamente". O mesmo autor não ignora que há obstáculos para ultrapassar devido a "uma heterogeneidade marcada em termos de desenho e organização de graus académicos, no credenciamento de instituições, organização de programas de pós-graduação, etc" (LAMARRA; GARCIA, 2015, p. 60). Também Brunner (2008, apud LAMARRA; GARCIA, 2015) aprofunda o tema e considera problemas que dificultam a implantação de um modelo universitário similar ao Processo de Bolonha na América Latina, entre outros:

A falta de um espaço comum a nível político, económico, monetário e do conhecimento; as questões geográficas já que países são "um mosaico de nações agrupadas pela geografia, mas separados por tudo o mais"; diferentes níveis e modelos de desenvolvimento, várias formas de integração no mundo global, tradições institucionais diferentes, diferentes visões do futuro; a tensão entre autonomia da universidade e autoridade do estado também limita a integração da educação superior e universitária na região. (LAMARRA; GARCIA, 2015, p. 61).

Sobre a tensão entre autonomia das IESs e autoridade do Estado, recorde-se que a Comissão Europeia apareceu historicamente como um novo ator supranacional, sendo que, para alguns autores, "o estabelecimento de políticas educativas a nível nacional é severamente restrito, dado que as prioridades nacionais devem ser conformes, pelo menos em termos genéricos, com os objetivos traçados a nível europeu" (KEELING, 2006, p. 214). Ou seja, segundo um modelo decisório do tipo top > down que pode ser ou não exequível em países da América Latina, a questão não é despicienda.

O que falta fazer? No entender de Lamarra, para o eventual sucesso do Espaço Comum Latino-Americano, seria necessário, entre outros, resolver aspetos relativos a políticas públicas, como "protocolos intergovernamentais para reconhecimento conjunto de dupla titulação de graus académicos pelas universidades latino-americanas, novas modalidades de governança das universidades, sistemas regionais e internacionais de bolsas de estudo, recuperar a discussão sobre o modelo B-M-D de Bolonha na definição de critérios comuns de estrutura académica ou ainda intercâmbio permanente de professores e investigadores" (LAMARRA; GARCIA, 2015, p. 62). Uma boa parte dessas medidas estão em linha com a experiência recente da construção do EEES. Em boa verdade, é precisamente neste quadro de reflexão partilhada, aproximação entre experiências diversas e mutuamente fertilizantes, que o projeto GIEPES no qual este estudo se enquadra tem a sua razão de ser. 


\section{REFERÊNCIAS}

BJERKE, Christian. Bologna 10 years on: the students' view. IAU Horizons, v. 16, n. 2, p. 18-9, set. 2010.

BERWANGER, Otávio; SUZUMURA, Erica A.; BUEHLER, Anna Maria; OLIVEIRA, João Bosco. Como avaliar criticamente revisões sistemáticas e metanálises? Revista Brasileira de Terapia Intensiva, v. 19, n. 4, p. 475-80, out./dez. 2007.

CACHAPUZ, António. A construção do Espaço Europeu de Ensino Superior: um case study da globalização. In: PEREIRA, Elisabete; ALMEIDA, Maria de Lourdes (Org.). Universidade Contemporânea: políticas do processo de Bolonha. Campinas, SP: Mercado das Letras, 2009. p. 13-26.

CARAÇA, João. À procura de um Portugal moderno. Lisboa: Campo das Letras, 2003.

GACEL-ÁVILA, Jocelyne. La dimensión internacional de las universidades. Contexto, procesos estratégias. Guadalajara: México, Universidad de Guadalajara, 2006.

COMUNICADO DE PARIS. Conferência Inter/Ministerial, 24/25 maio, Paris, França, 2018.

CROSIER, David; PURSER, Lewis; SMIDT, Hanne (Org.). TRENDS V: universities shaping the European Higher Education area. Brussels, Belgium: European University Association, 2007. Disponível em: https://eua.eu/downloads/publications/trends\%20v\%20universities\%20 shaping\%20the\%20european\%20higher\%20education\%20area.pdf. Acesso em: 13 mar. 2020.

DIAS SOBRINHO, José. Processo de Bolonha. Educação Temática Digital, Campinas, SP, v. 9, n. esp., p. 107-32, dez. 2007.

FLICK, Uwe. Introdução à pesquisa qualitativa. Porto Alegre: Artmed, 2009.

HUDZIK, John K. Comprehensive internationalization: from concept to action. Washington: NAFSA, 2011. Disponível em: http://ecahe.eu/w/images/1/1f/Comprehensive_ Internationalization_-_NAFSA.pdf. Acesso em: 13 mar. 2020.

KEELING, Ruth. The Bologna Process and the Lisbon Research Agenda: the European Commission: Expanding Role in Higher Education Discourse. European Journal of Education, v. 41, n. 2, p. 203-23, 2006.

LAMARRA, Norberto; GARCIA, Pablo. El desafío de innovar en la universidad Latinoamericana. Revista Internacional de Educação Superior, Campinas, SP, v. 1, n. 1, p. 50-65, jul./set. 2015. 
MAASSEN, Peter. The modernisation of Higher Education governance in Europe. In: AMARAL, Alberto (Ed.). Políticas do Ensino Superior. Lisboa: Conselho Nacional de Educação, 2008. p. 71-106.

OLIVEIRA, Teresa; HOLLAND, Stuart S. Retórica e realidades nas reformas de Ensino Superior e no Processo de Bolonha. Ensino Superior, n. 29, p. 19-23, 2008.

PEREIRA, Elisabete; ALMEIDA, Maria de Lourdes (Org.). Reforma universitária e a construção do espaço europeu de ensino superior. Campina, SP: Mercado das Letras, 2011.

PEREIRA, Elisabete; ALMEIDA, Maria de Lourdes (Org.). Universidade contemporânea: políticas do processo de Bolonha. Campinas, SP: Mercado das Letras, 2009.

SADLER, Michael. How far can we learn anything of practical value from the study of foreign systems of education. Comparative Education Review, v. 7, n. 2, p. 307-14, 1964 (reprinted).

SURSOCK, Andrée; SMIDT, Hanne (orgs). TRENDS 2010: a decade of change in European Higher Education. EUA, 2010. Disponível em: https://eua.eu/downloads/publications/ trends\%202010\%20a\%20decade\%20of\%20change\%20in\%20european\%20higher\%20 education.pdf. Acesso em: 13 mar. 2020.

WIT, Hans; HUNTER, Fiona. The future of internationalization of higher education. International Higher Education, n. 83, p. 2-3, out. 2015.

ZGAGA, Pavel. Bologna revisited: where and what next? IAU Horizons, v. 16, n. 2, p. 14-6, set. 2010.

\section{Sobre o autor:}

António Cachapuz: Professor catedrático (aposentado) da Universidade de Aveiro, Portugal. E-mail: cachapuz@ua.pt, Orcid: https://orcid.org/0000-0001-9112-6087

\section{Recebido em 15 de outubro de 2019.}

Aprovado para publicação em 14 de fevereiro de 2020. 